\title{
Local and Remote Unrelated Universities Partner on Industry-Taught Course
}

\author{
Dr. Charles E. Baukal Jr. P.E., John Zink Co. LLC
}

Dr. Chuck Baukal is the director of the John Zink Institute which is the training organization within the John Zink Company which manufactures industrial combustion equipment for a range of industries. Dr. Baukal has over 30 years of industry experience and is an adjunct instructor at 4 universities. He has authored/edited eight books on industrial combustion, has over 150 publications/presentations, is an inventor on eleven U.S. patents, and has a P.E. license.

\section{Prof. Geoffrey L Price, University of Tulsa \\ Prof. Geoffrey D. Silcox, University of Utah}

Prof. Silcox has been a member of the chemical engineering faculty at the University of Utah since 1987. His research interests include atmospheric particulate matter, controlling and characterizing the emissions of pollutants from the combustion of low quality fuels, and process modeling. He is currently teaching courses in thermodynamics and air pollution control engineering.

\section{Michael Newton, University of Utah, Chemical Engineering Department}

Michael Newton is a recent B.S. in Chemical Engineering graduate from the University of Utah. He had an emphasis in Energy Engineering and a Chemistry minor. Newton is a member of the Tau Beta Pi Engineering Honor Society and has received many departmental, college, and university scholarships. He worked with Dr. Jost O.L. Wendt of Utah for two years as a research assistant in the oxy-coal combustion group as part of the Institute for Clean and Secure Energy, helping three doctoral students' research efforts. His work was presented at the 2nd International Oxyfuel Combustion Conference in Yeppoon, Australia in September 2011. Additionally, Newton spent a summer taking part in the National Science Foundation's Research Experience for Undergraduates working as a student research associate for Oscilla Power, Inc. in Salt Lake City, Utah. His project with Oscilla Power, Inc. entailed a preliminary design and investigation into the corrosion protection of a novel wave energy harvester. Newton has also served as a teaching assistant for a Combustion Engineering course taught through the Chemical Engineering department at the University of Utah. Newton is excited to begin his graduate study in pursuit of a Ph.D. this year.

\section{Mr. Terry L Phipps,}

Terry L. Phipps is the owner of the Terry L. Phipps \& Company and First Team Video Display. He received a bachelor of science degree from Oklahoma State University in 1969. Phipps \& Company is a full-service video production company specializing in marketing, training and communications. Phipps video crews have traveled all over the U.S. shooting video for Regional, National and International clients producing programming, commercials, infomercials, streaming video, web design, on-line testing and training modules, marketing, sales and training video presentations. I have included the names of the major companies for which we are currently doing work. Phipps' Founder and President Terry L. Phipps has been involved in the television broadcast industry since 1971. His background includes a degree in Radio and TV Marketing from Oklahoma State University and service as a non- commissioned officer during the Vietnam conflict where he was awarded the Vietnamese Service Metal, the Vietnam Campaign Medal and the Bronze Star. In 1975, after four years as an account executive in sales for the NBC affiliate in Tulsa, he founded Phipps \& Company. Under Phipps' leadership, the company produced and syndicated three national outdoor shows, "Fishing with Roland Martin;" "Outdoors with Jimmy Houston;" and "Sports Tips" which featured: Tennis with John Newcombe, Snow Skiing with Billy Kidd, Golf with Chi Chi Rodriquez and Bowling with Don Johnson. Phipps \& Company was also heavily involved in the productions of television commercials, both local and national; corporate training and image tapes; and sporting events. In 1981, Phipps \& Company expanded its operation to include remote production with 
the construction of a 26-foot long, five camera mobile unit. During this time clients included: ESPN; Iowa State University Football and Basketball; Missouri Valley Conference Basketball; Mississippi State Football as well as the Kentucky Derby for WLKY-TV in Louisville, Kentucky. 1983 brought forth a major video project for Phipps in the formation of a separate remote company; Challenger Productions. Phipps, along with two other partners, constructed a three million dollar, "State of the Art" mobile unit, which at the time was the most sophisticated in the country. As vice president of Marketing, Phipps negotiated production contracts with all three television networks, as well as major cable networks; ESPN and USA. These contracts included: Monday Night Football for ABC, the Breeders' Cup for NBC and NCAA Midwestern Basketball Regional's for CBS. In 2002, Union High School in Tulsa, Okla. contracted Phipps \& Company to oversee the final stages of installing their Daktronics LED video board at the football stadium, provide a video production crew while helping them establish and train their own video department and staff. With the LED Display experience and Phillips' vast knowledge of the video production industry, First Team Outdoor Video Display was established in January 2005. To date, First Team Outdoor Video Display has installed LED video boards, video control rooms and football/basketball scoreboards in major Universities, Convention Centers and High School facilities across America. 
Local and Remote Unrelated Universities Partner on Industry-Taught Course

\begin{abstract}
Two unrelated universities and two companies partnered to deliver a chemical engineering elective course entitled Combustion Engineering. The course was taught by engineers from an industrial company. The course was taught face-to-face at a local university. The lectures were professionally videotaped by a multimedia company and put online for a distance course for students at a remote university. There were many benefits to the participants involved, but also some significant challenges. This paper discusses this unique multi-organization partnership including the lessons learned to improve future collaborations.
\end{abstract}

\title{
Introduction
}

There are many ways that industry and academia can collaborate to educate engineering students. Industry can provide individual instructors to teach existing courses as adjuncts or visiting professors. ${ }^{1}$ Industry can help provide new course content, for example for emerging technologies, which can be taught by academia. ${ }^{2}$ Adjunct instructors from industry can temporarily replace faculty on sabbatical or on leave, ${ }^{3}$ help handle temporary increases in student course enrollments, ${ }^{4}$ relieve full-time faculty so they can do research, ${ }^{5}$ or co-teach with full-time faculty to help bring professional practice into the classroom. ${ }^{6}$ Adjunct instructors can also teach specific topics in a course where faculty are less knowledgeable, ${ }^{7,8}$ teach entire courses outside the specific area of expertise of the faculty, ${ }^{4,9}$ and teach courses at off-campus locations. ${ }^{10}$ Industry can partner with universities to provide guest speakers to educate students about various aspects of the "real world" of engineering. ${ }^{11}$ Companies can host field trips where universities visit local industrial facilities to see actual equipment in operation. ${ }^{12}$ Cooperative positions and internships allow students to work side-by-side with engineering professionals to see how the principles learned in class are applied in actual practice. ${ }^{13,14}$ Industry sponsors senior design projects to produce some type of product of interest to them while simultaneously educating students by allowing them to apply their knowledge and skills to an actual problem. ${ }^{13}$ Some universities have used industry to help teach senior design courses as part of capstone projects, ${ }^{15}$ where these adjunct instructors are sometimes referred to as "Professors of Practice."16 Industry can sponsor research projects with faculty that also include student workers and can also provide facilities for students to conduct research if these are not available at the university. Industry can provide formal mentors for university students and participate in supervisory thesis committees for graduate students, ${ }^{9}$ including sponsoring industrial theses that are carried out in industry. ${ }^{11}$

A previous paper discussed an industry-university partnership that included an industrial company designing and teaching an engineering course at a local university [17]. John Zink Co. LLC (will also be referred to as the "industrial company”) located in Tulsa, Oklahoma developed and delivered an elective course of interest to the University of Tulsa (will also be referred to as the "local university") which did not have the specific expertise in the subject area. The course 
combined previously learned theory by the students in other engineering courses with a large component of application to a specific area of technology which in this case was industrial combustion. Zink engineers have been teaching this chemical engineering elective course annually at the University of Tulsa since 2009.

This type of collaboration has many benefits for all three primary stakeholders: the students, the university, and the industrial company. The students benefit by learning from experienced industry engineers, where most of the instructors have at least 10 years of industry experience and some more than 20. Each student receives a free copy of the course textbook, ${ }^{18}$ written by some of the instructors. The university can offer a course to their students in an area that is not a specific strength of its faculty. The cost to the university is very minimal as the instructors' time is donated by the industrial company. The relationship helps strengthen the ties between the local university and the industrial company which employs many graduates from the university. The industrial company has close access to top undergraduate and graduate chemical engineering students that are potential interns and permanent hires, which is an important motivation to deliver the course. More details on the benefits of this type of partnership are given in reference [17].

However, this type of collaboration also has some challenges. It is difficult for the students to develop any type of relationship with the instructors because they usually only meet for one or two class periods. The teaching styles of instructors vary, so adapting to the styles of multiple instructors can be somewhat challenging for the students. The grading standards may vary somewhat between instructors so students may be unsure of exactly what to expect. The quantity and complexity of assignments varies by instructor. None of the industry instructors has an office at the university or any set office hours. This makes it more difficult for students to discuss issues face-to-face after an instructor finishes teaching their subject in the course, although email is usually adequate to address most issues.

This paper discusses a variation of this partnership where the course delivered face-to-face to the same university was videotaped for a course delivered by distance to a remote university in the fall of 2012. There are many potential benefits of distance education such as increasing access to learning and training opportunities, improving cost effectiveness of educational resources, expanding the capacity for education in new subject areas, and greater schedule and learning flexibility. ${ }^{19,20}$

\section{Course Details}

The subject course is a three credit elective called Combustion Engineering. At both the local university (the University of Tulsa located in Tulsa, OK) and the remote university (the University of Utah located in Salt Lake City, UT), the course is offered in the chemical engineering department to advanced undergraduate and graduate students. The course includes 
both theory and application for technologies related to industrial combustion and pollution control. The course description is as follows:

Atmospheric pressure industrial combustion and related processes will be studied in this course. Approximately the first half of the course focuses on the fundamentals related to these processes including fuels, combustion chemistry, pollution emissions, fluid flow, and heat transfer. These are considered from the perspective of how they are used in industrial combustion. Some advanced course topics include computational fluid dynamics, liquid fuel atomization, noise and combustion testing. The last part of the course focuses on industrial combustion applications including flare gas recovery, biogas flaring, process flares, process heaters, thermal oxidizers, metallurgy, and equipment fabrication. Safety, the environment, and energy efficiency are important issues covered in the course.

The first half of the course is more theory-based, while the second half is more applicationsfocused. In the fall 2012 course, a dozen instructors taught the following topics in the order listed: combustion safety, heat transfer, fluid flow, noise, liquid fuel atomization, fuels, combustion chemistry, computational fluid dynamics, general pollution emissions, NOx emissions, thermal oxidizers, biogas flaring, combustion testing, flares, process heaters, process burners, flare gas recovery, metallurgy, and equipment fabrication. Some instructors taught multiple topics. Each topic was covered in one or two 75-minute face-to-face sessions taught twice a week at the local university. Two of the sessions, combustion testing and equipment fabrication, were held at the industrial company where students were given a lecture and then a tour of world-class combustion testing and manufacturing facilities (see Figure 1), respectively. All lectures including the tours were video-taped and uploaded to a server at the remote university for their students to watch at their convenience.

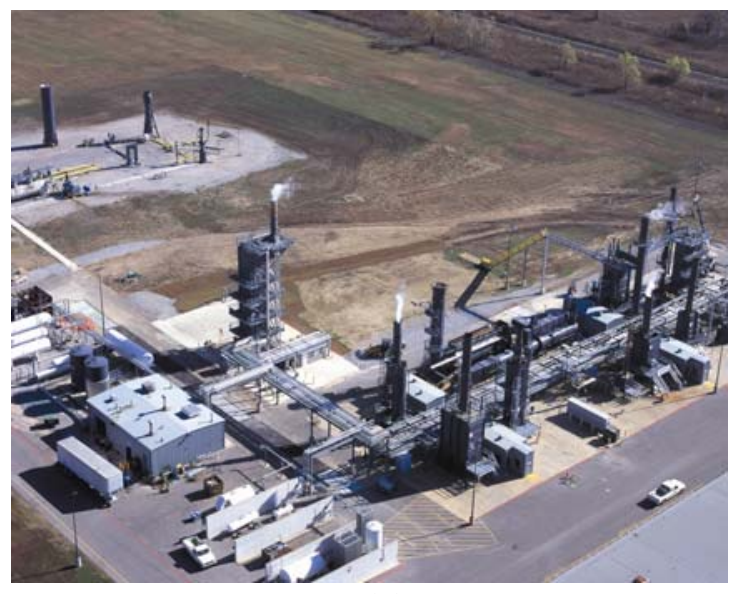

(a)

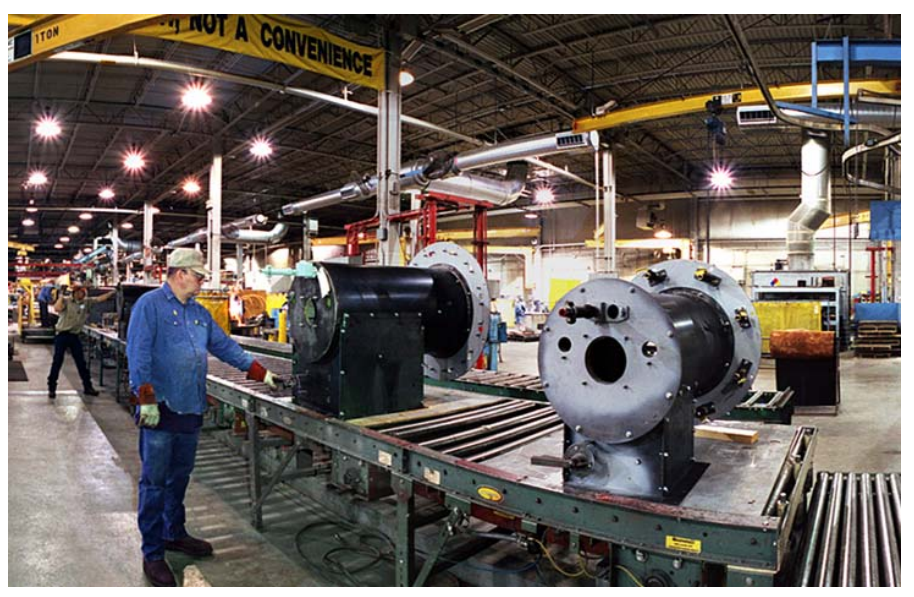

(b)

Figure 1. Photograph of John Zink’s (a) R\&D Test Center and (b) manufacturing facility.

Eight undergraduates from the local university and 24 undergraduates and 10 graduate students from the remote university took the course. Some of the graduate students were truly remotely 
located even from the remote university in Salt Lake City as they were working in the states of California and Washington, Belgium, and Mongolia at the time. The semesters at both the local and remote universities started on the same day. The local university had a one week fall break which the remote university did not. This was actually a benefit later in the course as it minimized the delay for the remote university students in receiving the lecture videos.

The local university students were given a large three-ring binder at the beginning of the course with only dividers containing the names of each topic to be covered. Each instructor provided a hard copy of their class notes for the students at the local university to insert into their binders. Dividers and electronic copies of the class notes were provided to the remote university students. The textbook ${ }^{18}$ for the course was written by the industrial company which manufactures equipment for a wide range of industries and is located a short distance from the local university. Copies of the textbook were provided at no charge by the industrial company to both the local and remote students.

The grade for the course was based on four equally-weighted components: quizzes and homework, a midterm exam, a non-cumulative final exam, and a project. The project consisted of a presentation and paper on a topic selected by the students from a prescribed list, although students could propose alternate topics subject to approval. The primary difference in course requirements for undergraduate and graduate students was related to the project where graduate students were required to produce longer and more scholarly papers compared to the undergraduates. The industrial company course coordinator traveled twice to the remote university: one day during the first week of classes to introduce the course and meet the students and one day at the end of the course to listen to the project presentations.

\section{Universities-Industries Collaboration}

The industrial company provided a dozen industry engineers to teach the course. All had considerable industrial work and teaching experience, although not all had previously taught at a university. All were instructors in the industrial company's training organization (the John Zink Institute) where the industrial company trains its employees and customers how to safely use its equipment while minimizing pollution and maximizing fuel efficiency and availability. ${ }^{21}$ The local university provided the classroom for the course face-to-face lectures.

A multimedia company, FirstTeam Video Inc. (located in Tulsa), was hired by the industrial company to professionally videotape the lectures and upload the videos to the server at the remote university. Figure 2 shows a photo of the front of the classroom as seen from just behind the video camera. The students at the local university preferred not to appear in the videos so they usually sat out of the view angle of the camera. 


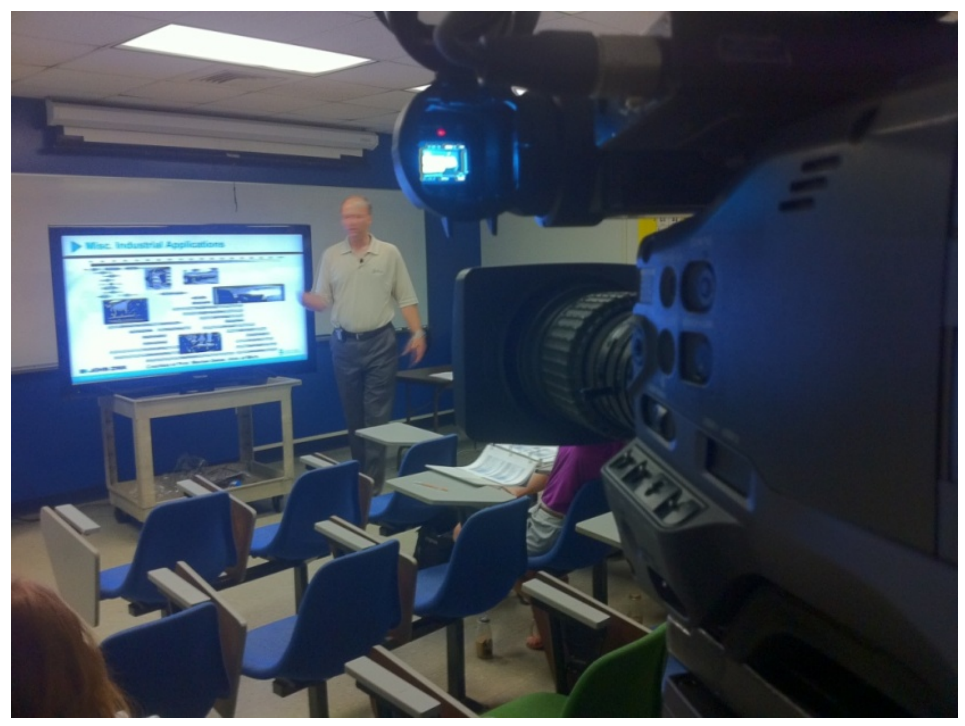

Figure 2. Photograph of the front of the classroom as viewed from just behind the video camera.

The remote university (the University of Utah) is internationally known for its combustion program and has many professors with expertise in this area of technology. The industrial company provides annual scholarships at the remote university and actively recruits there. The industrial company has funded research at the remote university as well. The remote university was aware that the industrial company teaches an applied combustion course at a local university as well as at another fairly close university (the University of Oklahoma in Norman, OK). The remote university inquired about the possibility of delivering the course online for their students, so they could get some exposure to practical combustion applications. Combustion Engineering would be a good complement to their existing combustion courses. The remote university agreed to provide a teaching assistant (TA) to help with the course logistics such as helping students access the lecture videos and to grade the assignments and exams. The industrial company course coordinator graded all projects from both universities for consistency.

While there was no direct interaction between the universities, the distance course would not have been possible unless the local university gave permission for the face-to-face classes to be videotaped. Students at the local university were given access to the lecture videos by the remote university. This proved to be advantageous for the local university students who had to miss a class because of other school activities or illness. Some also watched videos of classes they had actually attended to go over topics they may have been unsure about and to review for the exams. As will be discussed in more detail later, the multimedia company purchased a high definition television monitor for use in the classroom to display the lecture slides. The local university provided a lockable storage closet to store the monitor between class sessions. The multimedia company custom built a cart to handle the large monitor so it could easily be transported between the storage closet and the classroom. 
All organizations benefitted from this unique college-industry partnership. The primary interest of the industrial company is finding well-qualified candidates to hire. The local university does not have particular expertise in combustion, but has a history of supplying the industrial company with high quality engineering graduates to work in a broad range of roles, such as project management and manufacturing, that do not require prior combustion knowledge. The remote university has an internationally-recognized program in combustion and also has a history of providing the industrial company with high quality engineering graduates with combustion training. In fact, one of the course instructors is a graduate of the remote university. The local university was able to offer their students an elective in an area outside the faculty's expertise. The course showed the students how the theory they learned in previous courses such as heat transfer, fluid mechanics, and chemistry is applied to real-world problems. Exposure to the industrial company provided the local university students with potential job opportunities (at the time of this paper one was hired and another was offered an internship position). The city of Tulsa where the industrial company and the local university are located is well known for its employers in the area of combustion technology, so the local university students received valuable training of interest to other local employers as well. While the faculty at the remote university has considerable combustion expertise, they do not have as much practical experience as the industrial company, so their students, many of whom were specializing in the study of combustion, also saw how their previous theory courses could be applied in industry. Those students were also exposed to a potential employer; the industrial company plans to interview some of those students for positions.

\section{Lessons Learned}

The focus in this section is on the lessons learned from this multi-institution partnership. Lessons learned from the course taught by the industrial company at a local university are given elsewhere. ${ }^{17}$ There were some important lessons learned from the collaboration described here. The first is to ensure the video recordings are of adequate quality. The first lecture was recorded with the instructor using the standard projector and screen installed in the classroom. As seen in Figure 3, the video recording quality using the projector and screen was not as good as desired by the multimedia company. The projected image on the screen was washed out in the video. At their own expense in an effort to improve the quality, the multimedia company purchased a 60 in. high definition television to use as the monitor to display the lecture slides for the course. This size monitor was more than adequate for the relatively small classroom with only eight students. The improvement in the video quality was dramatic (see Figure 4), which benefitted both the local and the remote students. 


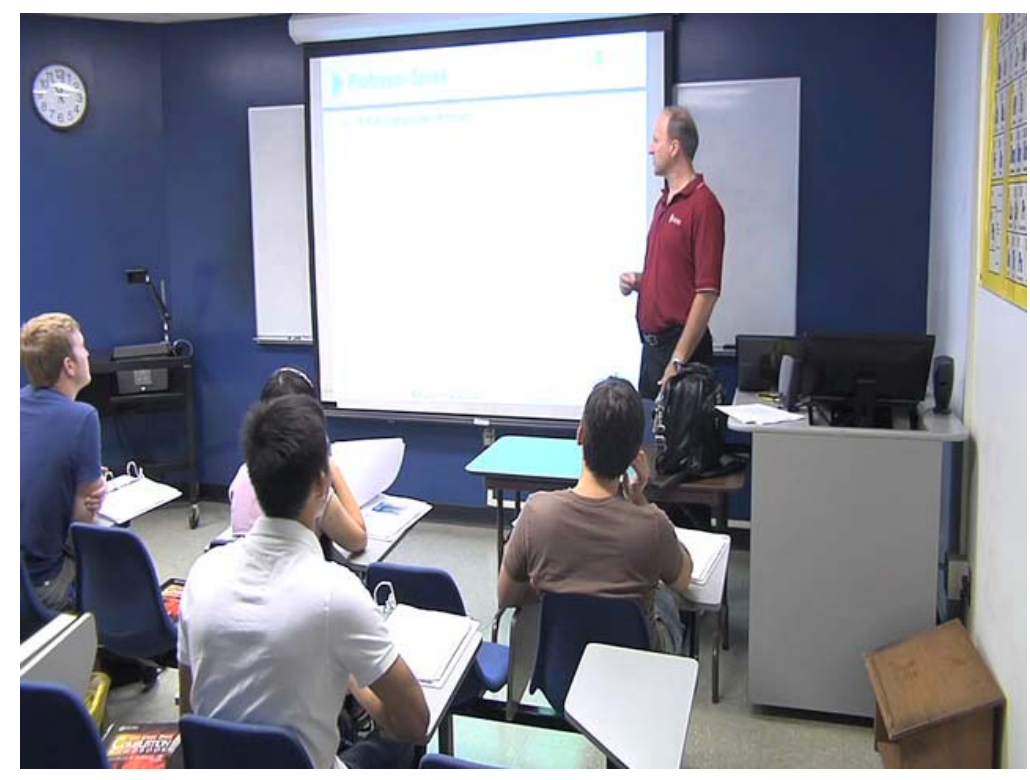

Figure 3. Washed-out image taken from the video recording using the projector and screen.

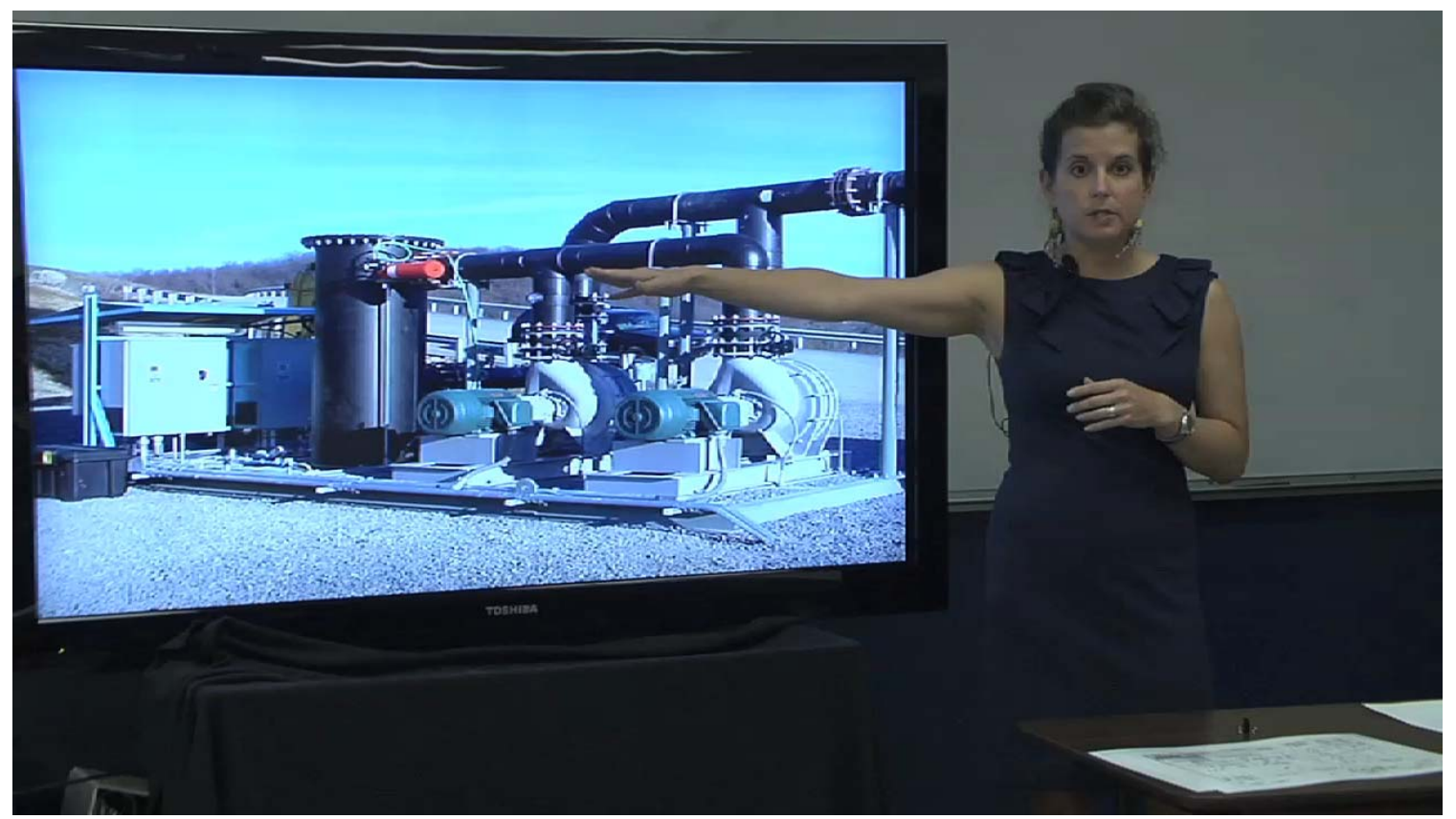

Figure 4. High quality mage taken from a video recording using the television as the monitor.

Another lesson learned was to test the method that will be used to handle the lecture video files. These were originally recorded as very high resolution mov files, some of which were over 100 GB in size. The high quality recordings were made so the videos could be used by the industrial company in the future as part of its training organization. These high resolution files were much too large to upload for students to view streaming online. The files were saved as lower resolution files that were still fairly large (up to 4 GB). These lower resolution files were uploaded to a server at the remote university. There were many difficulties with this process. 
Converting the high resolution files to lower resolution files took several hours or more. Uploading the files to the server usually took several more hours. If there were any transmission problems at all, the upload process would have to be restarted. There were also some files that were corrupted during the transmission process so they initially appeared to upload successfully only for students to later discover problems with them. For example, some videos would be fine for the first 20 minutes or so and then a problem would be encountered with the video (the audio still worked). Needless to say this was very frustrating for the students. Eventually, recordings were overnight mailed by the multimedia company to the remote university which increased the cost and delayed video uploading. A related problem was the students were unable to stream the videos and had to download each lecture to their computer. This again could take an hour or more for each video. Some of the students would go to campus on the weekend to download videos because it was so much faster then compared to during the normal school week. The online course is planned to be offered again at the remote university in the fall of 2013, so other methods are being investigated to make it much easier and more timely for the students to watch the lectures.

The distance course would not have worked very well without having a knowledgeable and effective teaching assistant (TA). The company teaches the course at the local university and at another fairly close university (about a $2 \mathrm{hr}$ drive) without a TA as the instructors grade their own assignments. This works well for the smaller class sizes of no more than about a dozen students. However, because of the significantly larger class size at the remote university and because of the added logistical issues related to distance courses, a TA was essential.

\section{Conclusions and Recommendations}

Four institutions, two from academia and two from industry, collaborated to deliver both a faceto-face and a distance version of a chemical engineering elective course entitled Combustion Engineering. All stakeholders benefitted in some way from this unique alliance. The students received free textbooks and saw how the theory they learned in other courses was applied to a specific area of industrial technology. They were also exposed to a potential employer to see if the company might be a fit for them after graduation. The remote students were able to "attend class" at their convenience. Some stated they would not have been able to take the course otherwise due to their schedules. The universities were able to offer an elective of interest to their students at very little cost. Engineers from the industrial company involved in hiring new graduates were able to more closely observe students from two well-respected universities to see which might be potential candidates to hire for both internships and permanent positions. The multimedia company added to their experience by learning how to produce high quality lecture videos in a classroom setting at a very reasonable cost. As a result of this project, the industrial company hired the multimedia company to produce other educational videos for the company's training organization. 
There were also some important lessons learned for future collaborations. The first is to make a test lecture video if at all possible well before the start of the class to make sure the quality is adequate. The second is to ensure the delivery of the lecture videos is timely and robust to minimize the frustration to online students. The third is to have someone knowledgeable at the remote site who can handle logistical issues that usually arise. End-of-course evaluations from the remote university showed the students were generally satisfied with the course. Most of the written comments concerned the lecture video delivery problems.

This engineering education project required significant collaboration and flexibility on the part of all organizations involved. While all had previously worked in different aspects of similar projects, none had participated in this type of multi-organization relationship. Plans are already being made to improve this collaboration for future offerings of the course.

\section{Bibliography}

1. N.A. Lewis, The engineer as a professor: Bringing experience to the engineering classroom, presented at the ASEE Mid-Atlantic Section meeting, U.S. Military Academy at West Point (New York), March 28-29, 2008.

2. K. Korhonen-Yrjänheikki, T. Tukiainen, and M. Takala, New challenging approaches to engineering education: Enhancing university-industry co-operation, European J. Engineering Education, Vol. 32, No. 2, pp. 167-179, 2007.

3. J.P. Gosink and R.A. Streveler, Bringing adjunct engineering faculty into the learning community, $J$. Engineering Education, Vol. 89, No. 1, pp. 47-51, 2000.

4. A. Rose and N. Voigt, The role of adjunct faculty in future engineering, proceedings of the 2008 American Society for Engineering Education Annual Conference \& Exposition, paper AC 2008-2046.

5. V. Varma, Practitioners as adjunct clinical professors: Their role in teaching real-world engineering applications in design and construction, proceedings of the 2009 American Society for Engineering Education Annual Conference \& Exposition, paper AC 2009-304.

6. W. Akili, Integrating practical experience in a geotechnical/foundation engineering class: The role of the adjunct faculty, proceedings of the 2005 American Society for Engineering Education Annual Conference \& Exposition, pp. 8423-8436.

7. P. Dunn, Creating industrial partnerships with construction-management technology programs, proceedings of the 2009 American Society for Engineering Education Annual Conference \& Exposition, paper AC 20091114.

8. K. McManus, The effects of integration of industry faculty into a construction management postgraduate coursework program in the Australian environment, proceedings of the 2007 American Society for Engineering Education Annual Conference \& Exposition, paper AC 2007-1562.

9. F.S. Gunnerson, R.T. Jacobsen and G. Pillay, A strategic alliance between regional universities and industry at a national laboratory, proceedings of the 2002 American Society for Engineering Education Annual Conference \& Exposition, pp. 3895-3903.

10. J.V. Farr and D. Verma, Involving industry in the design of courses, programs, and a systems engineering and engineering management department, proceedings of the 2002 American Society for Engineering Education Annual Conference \& Exposition, pp. 495-502.

11. W.W. Massie, Bringing practitioners (and practice) into the curriculum, proceedings of the 2004 American Society for Engineering Education Annual Conference \& Exposition, pp. 1303-1311.

12. D.J. Fournier and C. Gaudet, Creating relationships with industry to advance new programs, proceedings of the 1999 American Society for Engineering Education Annual Conference \& Exposition, pp. 1405-1410. 
13. Z.O. Keil and M. Basantis, An industrial internship program to enhance student learning and marketability, proceedings of the 2000 American Society for Engineering Education Annual Conference \& Exposition, pp. 845-850.

14. I. Dabipi and J. Arumala, Enhancing engineering education through real-life projects, proceedings of the 2007 American Society for Engineering Education Annual Conference \& Exposition, paper AC 2007-3031.

15. R.C. Knox, D.A. Sabatini, R.L. Sack, R.D. Haskins, and S.W. Fairbairn, A practitioner-educator partnership for teaching engineering design, J. Engineering Education, Vol. 84, No. 1, pp. 1-7, 1995.

16. J. Ochs, G. Lennon, T. Watkins, and G. Mitchell, A comprehensive model for integrating entrepreneurship education and capstone projects while exceeding ABET requirements, proceedings of the 2006 American Society for Engineering Education Annual Conference \& Exposition, paper AC 2006-1330.

17. C. Baukal, J. Colannino, W. Bussman, and G. Price, Industry Instructors for a Specialized Elective Course, Paper AC 2010-67, proceedings of 2010 American Society for Engineering Education conference, June 2023, 2010, Louisville, KY.

18. C.E. Baukal (ed.), The John Zink Combustion Handbook, CRC Press, Boca Raton, FL, 2001.

19. M. Moore and G. Kearsley, Distance Education: A Systems View, Second Edition, Thomson Wadsworth, Belmont, CA, 2005.

20. S.T. Muench, Self-managed learning model for civil engineering continuing training, Journal of Professional Issues in Engineering Education and Practice, Vol. 132, No. 3, pp. 209-216, 2006.

21. C.E. Baukal and M. Crawford-Fanning, Combustion Training, Chapter 17 in The John Zink Hamworthy Combustion Handbook, $2^{\text {nd }}$ ed., edited by C.E. Baukal, CRC Press, Boca Raton, FL, 2013. 